\title{
Antibiotic Resistance, Plasmids and Integron Profile of Salmonella Species Isolated from Poultry Farm and Patients
}

\author{
Kohinur Begum ${ }^{1}$, Sultana J uhara Mannan ${ }^{1}$ and Aliza Ahmed ${ }^{2}$ \\ ${ }^{1}$ Department of Pharmacy, ASA University Bangladesh, ASA Tower, Shyamoli, Dhaka-1207, Bangladesh \\ ${ }^{2}$ Department of Pharmacy, University of Asia Pacific, Dhaka, Bangladesh
}

(Received: October 05, 2016; Accepted: December 08, 2016; Published (web): December 27, 2016)

\begin{abstract}
A total of ten selected strains of Salmonella species, five from the environment of poultry farm and five from patients were included in this study. All strains were isolated and identified by using selective media, standard biochemical and serological tests. Antimicrobial susceptibility tests were performed by disc diffusion method using twelve commercial antibiotic discs of aztreonam, ceftriaxone, kanamycin, ciprofloxacin, gentamycin, chloramphenicol, ampicillin, erythromycin, cephalexin, tetracycline, cotrimoxazole and nalidixic acid. Plasmid profile and integron gene detection were conducted by Kado-Liu method and PCR, respectively. Only aztreonam, ceftriaxone, kanamycin and gentamycin were shown to be inhibitory to all strains. However, ciprofloxacin, chloramphenicol, amoxicilin, erythromycin, cephalexin, tetracycline, cotrimoxazole and nalidixic acid revealed different degrees of resistance pattern against environmental and clinical strains. Analysis of plasmid demonstrated that three environmental strains contained both plasmids of $140 \mathrm{Mda}$ and $62 \mathrm{Mda}$. On the other hand, another three strains, one environmental and two clinical isolate only contained 140 Mda plasmid. All the plasmid containing strains (140 Mda and $62 \mathrm{Mda}$ ) exhibited same type of drug resistance pattern, whereas strains containing the $140 \mathrm{Mda}$ plasmid only did not show similar type of resistance pattern. Therefore, no correlation was found between plasmid containing strains and drug resistance. Four environmental strains were also found to be positive for the class I integron and one clinical isolated was positive for class I integron gene conferring resistance to common antibiotics. However, none of the strains were found to contain class II integron. Therefore, the present study demonstrated that both environmental and clinical strains contain both large to middle size plasmids and integron I but not integron II. The plasmid and integron I containing strains experienced resistance to different antibiotics, used in the experiments.
\end{abstract}

Key words: Antibiotic resistance, plasmid, integron I and II gene, Salmonella species.

\section{INTRODUCTION}

A potential fatal illness both typhoidal and non typhoidal is caused by different serotypes of Salmonella worldwide. Contaminated food of animal origin and food-producing animals cause salmonella infection. ${ }^{1}$ The most prevalent serovars found in feed products causes disease in human or animals and they survive in different environments. ${ }^{2,3}$ However, Foodborne gastroenteritis, diarrhea and even septicemia occur in human and animals due to these causative agents. Drugs used for treatment of salmonellosis include trimethoprim / sulfamethoxazole, ampicillin

Correspondence to: Kohinur Begum

E. mail: prof.kohinur@asaub.edu..bd / kohinur025@yahoo.com

Dhaka Univ. J. Pharm. Sci. 15(2): 209-214, 2016 (December) or amoxicillin, ceftriaxone, cefotaxime and cephalosporin. ${ }^{4}$ Many reports have been focused on the antimicrobial resistance phenotypes among Salmonella serovars of different origins., ${ }^{3,5-7}$ Antibiotic resistance has been found to be increasing for several decades. ${ }^{8}$ Different reports have shown that the genetic elements such as plasmids and integrons, which disseminate antibiotic resistance genes by horizontal or vertical transfer play an important role for evolution of multidrug resistance. ${ }^{9-12}$ Resistant genes are found to be located on extra chromosomal genetic elements or in segments inserted within the chromosome that originate from other genome. However, resistant genes encoded in plasmids are often located within 
genetic elements. ${ }^{13}$ Integrons are very common in $S$. enterica and significantly contribute to antimicrobial resistance in Salmonella species. ${ }^{13-14}$ Extensive studies are required for antimicrobial resistant strains isolated from environment and human or animals. In this study, an attempt has been taken to correlate antibiotic resistance, plasmids and integron profile of Salmonella species isolated from poultry environments and patients.

\section{MATERIALS AND METHODS}

Bacterial strains. Ten selected strains of Salmonella species, five from environmental poultry farm (chicken feces) and five from patients (blood) were obtained from our laboratory stock in this study. ${ }^{3}$ Briefly, samples were enriched in selenite broth at $37{ }^{\circ} \mathrm{C}$ for overnight and incubated at $37{ }^{\circ} \mathrm{C}$ for 18-24h on SS agar plate and characteristic yellow colonies were isolated and sub-cultured again in MacConkey agar plate for discrete colonies. Suspected single colonies were identified as Salmonella sp. by biochemically according to standard microbiological method and confirmed by serologically the slide agglutination test as described previously using commercially available antisera kit (Denka Saiken, Co. Ltd. Japan). ${ }^{15}$

Antibiotic susceptibility test. Antibacterial susceptibility test were performed by the KirbyBauer disc diffusion method on Muller-Hinton agar plates. Twelve commercially available antibacterial discs (Himedia, India) were used including ampicillin (AMP, $25 \mu \mathrm{g}$ ), aztreonam (AT, $30 \mu \mathrm{g}$ ), ceftriaxone (CTR, $30 \mu \mathrm{g})$, cephalexin (CN,30 $\mu \mathrm{g})$, ciprofloxacin (CIP, $5 \mu \mathrm{g}$ ), chloramphenicol (C, $30 \mu \mathrm{g})$, cotrimoxazole (COT, $25 \mu \mathrm{g}$ ), erythromycin (E, 15 $\mu \mathrm{g})$, kanamycin (K, $30 \mu \mathrm{g})$, tetracyline (TE, $30 \mu \mathrm{g}$ ), nalidaxic acid (NA, 30 $\mathrm{g}$ ) and gentamycin

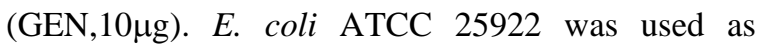
control strain for susceptibility test.

Detection of plasmid DNA. Plasmid DNA of all strains was prepared according to the alkaline lysis method of Kado and Liu (1981) ${ }^{16}$, with some modifications. An isolated colony of each strain was inoculated into $1.5 \mathrm{ml}$ of Luria broth overnight at 37
${ }^{\circ} \mathrm{C}$ with shaking condition (120 rpm/min). Cells were harvested by centrifugation at $14,000 \mathrm{rpm}$ for 1 -2 minutes. The cells were then suspended in $100 \mu \mathrm{l}$ of solution I (40 mMTris-NaOAc, 2 mM EDTA, pH 7.4) and $200 \mu \mathrm{l}$ of solution II (3\% SDS, 50 mMTris, $\mathrm{pH}$ 12.9) was added and mixed by inverting tubes up and down. The tubes were then incubated at $55{ }^{\circ} \mathrm{C}$ for 1h. After incubation, an equal volume of solution III [(phenol: chloroform: isoamyl alcohol (25:24:1)] was added, mixed well and plasmid DNA was collected by centrifugation at $14000 \mathrm{rpm}$ for $10 \mathrm{~min}$. The upper phase (plasmid DNA) were recovered by pasteur pipette and transferred to a fresh tube. Plasmid DNA was separated by horizontal electrophoresis in $0.7 \%$ agarose slab gels in a Tris-borate EDTA (EDTA) buffer at room temperature at 100 volt $(50 \mathrm{~mA})$ for 3 h. After electrophoresis, the gels were stained with $0.5 \mu \mathrm{g} \mathrm{ml}^{-1}$ concentration of ethidium bromide and the gel was viewed and photographs were made. The molecular mass of the plasmid DNA bands were assessed by comparing with the mobility of known molecular mass plasmids in E. coli PDK-9 containing $140 \mathrm{MDa}$, E. coli V517 containing 35.8, 4.8, 3.7, 3.4, 3.1, 2.0, 1.8 and 1.4 MDa and Shigella flexneri $1 \mathrm{C}$ containing 140 and 62 MDain agarose gels. ${ }^{16}$

Detection of integron genes by PCR assay. Detection of integron class I and II was performed by PCR and the primers used in the amplification reaction were synthesized by using Oligo 1000 DNA synthesizer in the Enteric Bacteriology Laboratory, ICDDRB. For identification of integron class I and II gene, $3 \mu \mathrm{l}$ of template DNA was added in $27 \mu \mathrm{l}$ of reaction mixer containing $3 \mu$ of $10 \mathrm{X}$ PCR buffer, 1 $\mu \mathrm{l}$ of $50 \mathrm{mM} \mathrm{MgCl} 2,2 \mu \mathrm{l}$ of $2.5 \mathrm{mMdNTP}, 1 \mu \mathrm{l}$ of primer (reverse and forward) together with 1 unit of Taq DNA polymerase (5 U/ $\mu \mathrm{l})$. The class 1 integron primers, 5'-conserved segment (CS) and 3'-CS, which amplify the region between the 5-CS and 3-CS of class 1 integrons, were used as previously described (Table 1). For the detection of class 2 integrons, PCR was performed with the primer pair, hep74 and hep51, specific to the conserved regions of class 2 integrons, as described previously (Table 1).Volume of the reaction mixture was adjusted by adding filtered deionized water. Boiled culture of 
selected strains were used as template DNA, which was prepared by inoculating single, isolated colony of overnight culture into $200 \mu \mathrm{l}$ of normal saline and then by boiling for $10 \mathrm{~min}$. PCR assays were performed in a DNA thermal cycler (model 480; perkin-Elmer Cetus, Emeryville, Calif.) with the following program: Predenaturation at $94{ }^{\circ} \mathrm{C}$ for 10 min, followed by 35 cycles of $94^{\circ} \mathrm{C}$ for $1 \mathrm{~min}$ and 72 ${ }^{\circ} \mathrm{C}$ for 5 min with a final extension step at $72{ }^{\circ} \mathrm{C}$ for 5 min. S. typhi strain sensitive to all antibiotics was used as negative control. The amplified DNA products were analyzed by conventional $1.5 \%(\mathrm{wt} / \mathrm{v})$ agarose gel electrophoresis in 0.5 X TBE buffer and stained with ethidium bromide as outlined above. Electrophoretic separation, visualization of amplified product and photographs were made.

\section{RESULTS AND DISCUSSION}

As the epidemiology of salmonellosis began to unknown, it became apparent that food played an important part in the chain of infection. Salmonella is the most prevalent bacteria in the environment, found in the water and soil and in the intestinal tract, on the skin of humans and all other animals and birds. The prevalence of Salmonella is sometimes found in raw food such as meat, fish, poultry eggs, unpasteurized milk and raw vegetable. The salmonella infection may spread from the intestine to the blood stream, and then to other body sites and can cause death unless the person is treated promptly with antibiotics. The elderly, infants, and those with impaired immune systems are more likely to have a severe illness. In our previous study, different Salmonella serogroup and type were isolated from poultry environments, chicken eggs and intestines and found resistant to different antibiotics. ${ }^{3}$ A comparative study of selected strains was made for correlation among plasmid, integron gene and drug resistance in this study. Strains showed multi drug resistance to different antibiotics (Figure 1). All the strains (100\%) were resistant to ampicillin and erythromycin. $90 \%$ strains were resistance to both cephalexin and tetracycline. $70 \%$ strains were resistant to cotrimoxazole and nalidixic acid. However, $10 \%$ and $40 \%$ strains were resistant to ciprofloxacin and chloramphenicol, respectively.

Table 1. Primer pairs for integron PCR and sequencing.

\begin{tabular}{llll}
\hline Primer & Sequence (5' to 3') & Target & Reference \\
\hline 5'-cs & GGC ATC CAA GCA GCA AG & Class 1 & 21 \\
3'-cs & AAG CAG ACT TGA CCT GA & integron & \\
hep74 & CGGGATCCCGGACGGCATGCACGATTTGTA & Class 2 & 22 \\
hep51 & GATGCCATCGCAAGTACGAG & integron & \\
\hline
\end{tabular}

Table 2. Plasmid profile, integron and resistance pattern of Salmonella strains.

\begin{tabular}{llccl}
\hline Strain no & $\begin{array}{l}\text { No of plasmid } \\
(\mathrm{Mda})\end{array}$ & Integron I & Integron II & Antibiotic resistant pattern \\
\hline E5 & 140,62 & + & - & AMP, COT, CN, E, NA, TE \\
E18 & 140,62 & + & - & AMP, COT, CN, E, NA, TE \\
E21 & 140,62 & + & - & AMP, COT, CN, E, NA, TE \\
E27 & 140 & + & - & AMP, CIP, COT, CN, E, NA, TE \\
E32 & - & - & - & AMP, CN, E, NA, TE \\
C3 & - & - & - & AMP, C, COT, CN, E, NA, TE \\
C5 & - & - & - & AMP, CN, E, TE \\
C9 & - & - & - & AMP, CN, E, TE \\
C12 & 140 & - & - & AMP, C, COT, CN, E,TE \\
C15 & 140 & + & - & AMP, C, COT, E, NA, TE \\
$+=$ positive, - = negative, & & & \\
\hline
\end{tabular}






Figure 1. Percentages of antibiogram of Salmonella strains.
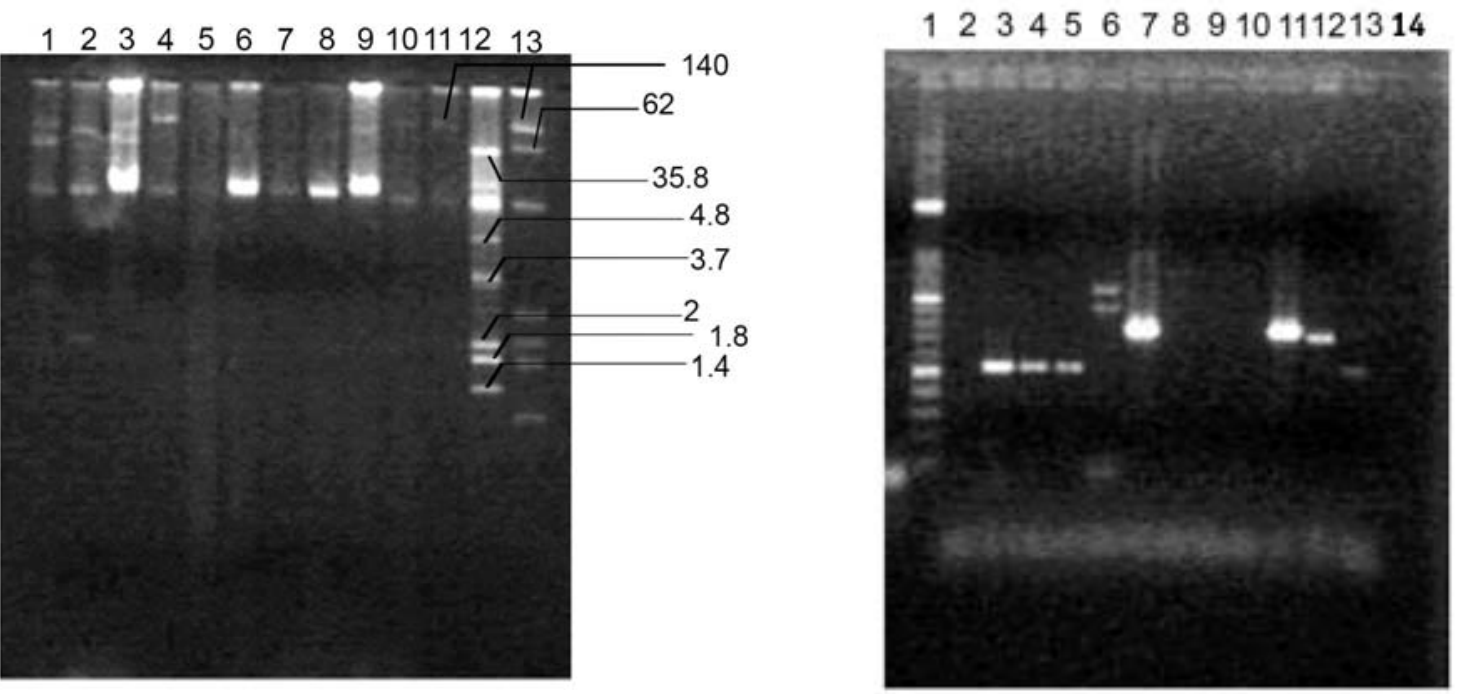

Figure 2. Detection of plasmids of Salmonella stains. Lane- 1 (E5), Lane- 2 (E18), Lane-3 (E21), Lane-4 (E27), Lane-5 (E32), Lane-6 (C3), Lane-7 (C5), Lane-8 (C9), Lane-9 (C12), Lane-10 (C15) and lane 11, 12, 13 are molecular marker of $E$. coli PDK-9, E. coli V-517, and Shigella flexneri 1C, respectively

Antibiotic susceptibility pattern have shown almost same between environmental and clinical strains, however one strain (E27) showed resistance to ciprofloxacin isolated from environment (Table 2). The widespread use of antimicrobials in human and animals are often implicated in the emergence of multidrug-resistant organism. The occurrence of multidrug resistance (MDR) to ampicillin, chloramphenicol, sulfonamides, streptomycin, tetracycline, and trimethoprim in Salmonella enterica serovar typhi has been increasing and MDR strains have been responsible for outbreaks on the Asian
Figure 3. Detection of integron genes. Lane-1 molecular weight marker, Lane-2 (Blank), Lane-3 (E5), Lane-4 (E18), Lane-5 (E21), Lane-6 (E27), Lane-7 (E32), Lane-8 (C3), Lane-9 (C5), Lane-10 (C9), Lane-11 (C12), Lane-12 (C15); Lane13 and Lane-14 are positive and negative control, respectively.

subcontinents. ${ }^{17}$ In a multinational study in Denmark, Germany, Italy, Spain and the United States and another study in France, thus confirmed the spread and persistence of this multidrug-resistant for epidemic strain of $S$. enterica serotype typhimurium. ${ }^{18,19}$

Six out of ten strains contained plasmids ranging from 140-62 MDa and the result has been shown in table 2 and figure. 2. E5, E18 and E21 strains contained both large size plasmid $140 \mathrm{MDa}$ and middle size plasmid 62 MDa. One environmental strain E27 contained only one large size plasmid 140 
MDa. On the other hand, C12 and C15 strains possessed only large size plasmid $140 \mathrm{MDa}$ isolated from patient. Strain E32 isolated from environment and C3, C5 and C9 from clinical strains did not possess any plasmid. Plasmids and transposons containing organisms showed antibiotic resistance by various mechanisms. In recent years, the role of integrons and gene cassettes in the spread of antibiotic resistance has been well established. ${ }^{20}$ Class I integrons are the most extensively studied integrons, which are thought to be a major factor implicated in the dissemination of antibiotic resistance. Class I integron contained a single gene cassette $d f r V I I$ or aadA1confering resistance to trimethoprim or spectinomycin and streptomycin respectively. Moreover, the $d f r V I I$ gene cassette was found in S. typhi associated with an incompatibility plasmid. ${ }^{17}$ In this study, four stains (E5, E18, E21 and E27) isolated from poultry faeces and one stain (C15) isolated from patients were found to be positive for class I integron (Figure 3) conferring resistance to common antibiotics such as ampicillin, cotrimoxazole, cephalexin, erythromycin, nalidixic acid and tetracycline. Stains E32, C3, C5 and C9 did not contain any plasmid and integron I but found to be different antibiotic resistance (Table 2). On the other hand, one sample (C12) showed plasmid and did not contain any integron but possessed different antibiotic resistance. None of the strains in this study contained class II integrons.

\section{CONCLUSION}

In the present study, Sallmonella sp. have shown multi-drug resistance to different antibiotics and revealed almost same results for both environmental and clinical isolates. The strains possessed plasmid ranging from large to middle size and integron I gene but none of the strains contained integron II gene. However, no correlation was found between the plasmid profile, integron I or II and antibiotic resistance. However, further investigation is needed to identify the specific gene cassette and their contribution in antibiotic resistance.

\section{REFERENCES}

1. Shirota, K., Katoh, H., Murase, T., Ito, T. and Otsuki, K. 2001. Monitoring of layer feed and eggs for Salmonella in Eastern Japan between 1993 and 1998. J. Food Prot. 64, 734-737.

2. Lindqvist, N., Heinikainen, S., Toivonen, A.M. and Pelkonen, S. 1999. Discrimination between endemic and feedborne Salmonella Infantis infection in cattle by molecular typing. Epidemiol. Infect. 122, 497-504.

3. Begum, K., Reza, T.A., Haque, M., Hossain, A., Hassan, F.M.K., Hasan, S.N., Akter, N., Ahmed, A. and Barua, U. 2010. Isolation, identification and antibiotic resistance pattern of Salmonella Spp. from chicken eggs, intestines and environmental samples. J. Pharm. Bangladesh. 13, 23-27

4. Hohmann, E.L. 2002. Nontyphoidal salmonellosis. Clin. Infects. Dis. 15, 263-269.

5. Esaki, H., Morioka, A., Ishihara, K., Kojima, A., Shiroki, S., Tamura, Y. and Takahashi, T. 2004. Antimicrobial susceptibility of Salmonella isolated from cattle, swine and poultry (2001-2002): report from the Japanese veterinary antimicrobial resistance monitoring program. J. Antimicrob Chemother. 53, 266-270.

6. Esaki, H., Morioka, A., Kojima, A., Ishihara, K., Asai, T., Tamura, Y., Izumiya, H. and Terajima, J. 2004. Epidemiological characterization of Salmonella Typhimurium DT104 prevalent among food-producing animals in the Japanese veterinary antimicrobial resistance monitoring program (1999-2001). Microbiol. Immunol. 48, 553-556.

7. Zhao, S., McDermott, P.F., White, D.G., Qaiyumi, S., Friedman, S.L., Abbott, J.W., Glenn, A. and Ayers, S.L. 2007. Characterization of multidrug resistant Salmonella recovered from diseased animals. Vet. Microbiol. 123, 122132.

8. Center for Disease Control and Prevention. 2007. National Antimicrobial Resistance Monitoring System for Enteric Bacteria (NARMS): Human Isolates Final Report, 2004. U.S. Department of Health and Human Services, CDC, Atlanta, Georgia.

9. Gomez, T.M., Motarjemi, Y., Miyagawa, S. and Kaferstein, F.K. 1997. Foodborne salmonellosis. World Health Stat. Q. 50, 81-89.

10. Liebert, C.A., Hall, R.M. and Summers, A.O. 1999. Transposon Tn21, flagship of floating genome. Microbiol. Mol. Biol. Rev. 63, 507-522.

11. Boyd, D., Peters, G.A., Cloeckaert, A., Boumedine, K.S., Chaslus-Dancla, E., Imberechts, H. and Mulvey, M.R. 2001. Complete nucleotide sequence of a 43-kilobase genomic island associated with the multi drug resistance region of Salmonella T 120 and serovar Agona. J. Bacteriol. 183, 5725-5732.

12. Boyd, D., Cloeckaert, A., Chaslus-Dancla, E. and Mulvey, M.R. 2002. Characterization of variant Salmonella genomic island 1 multidrug resistance regions from serovars Typhimurium DT104 and Agona. Antimicrob. Agents Chemother. 46, 1714-1722. 
13. Carattoli, A. 2003. Plasmid-mediated antimicrobial resistance in Salmonella enterica. Curr. Mol. Biol. 5, 113-122.

14. Caratoli, A., Villa, L.,Pezzella, C., Bordi, E. and Visca, P. 2001. Expanding Drug Resistance through integron acquisition by IncFI plasmids of Salmonella enteric Typhimurium. Emerg. Infect. Dis. 7, 444-447.

15. El-Gendy, A., El-Ghorab, N., Lane, E.M., Elyazeed, R.A., Carlin, N.I.A., Mitry, M.M., Kay, B.A., Savarino, S.J. and Peruski,L.F.Jr. 1999. Identification of Shigellaflexneri sub serotype 1c in rural Egypt. J. Clin. Microbiol. 37, 873-874.

16. Talukder, K.A., Islam, M.A., Dutta, D.K., Hassan, F. and Safa, A. 2002. Phenotypic and genotypic characterization of serologically atypical strains of Shigellaflexneri type 4 isolated in Dhaka, Bangladesh. J. Clin. Microbiol. 40, 24902497.

17. Poly, M.C., Chainier, D., Tran Thi, N.H., Poilane, I., Cruaud, P., Denis, F., Collignon, A. and Lambert, T. 2003. Integron Associated antibiotic resistance in Salmonella enteric serovartyphi from Asia. Antimicrob. Agents Chemother. 47, 1427-1429.

18. Baggesen, D.L., Sandvang, D. and Aarestrup, F.M. 2000. Characterisation of Salmonella enteric serovar Typhimurium DT104 isolated from Denmark and comparison with isolates from Europe and the United States. J. Clin. Microbiol. 38, 1581-1586.
19. Lailler, R., Gromint, F., Jones, Y., Sanders, P. And Brisabois, A. 2002. Subtyping of Salmonella Typhimurium pulsed-field gel electrophoresis and comparisons with phage types and resistance types. Pathol. Biol. 50, 361-368.

20. Zhang, H.M., Shi, L., Li., L., Guo, S.Y., Zhang, X.M., Yamasaki, S., Miyoshi, S. and Shinoda, S. 2004. Identification and characterization of class 1 integron resistance gene cassettes among Salmonella strains isolated from healthy humans in China. Microbiol. Immunol. 48, 639645.

21. Le'vesque, C., Piche', L., Larose, C. and Roy, P.H.1995. PCR mapping of integrons reveals several novel combinations of resistance genes. Antimicrob. Agents Chemother. 39, 185-191.

22. White, P.A., McIver, C.J. and Rawlinson, W.D. 2001. Integrons and gene cassettes in the Enterobacteriaceae. Antmicrob. Agents Chemother. 45, 2658-2661. 